\title{
Impact of High Energy Nutritional Supplement Drink consumed for five consecutive days on cardio metabolic risk factors in underweight females
}

\author{
S. Fatima ${ }^{1}$, K. Gerasimidis ${ }^{1}$, C. Wright ${ }^{2}$ and D. Malkova ${ }^{1}$ \\ ${ }^{1}$ School of Medicine College of Medical, Veterinary and Life Sciences (MVLS), New Lister Building, Glasgow Royal \\ Infirmary 10-16 Alexandra Parade, Glasgow G31 2ER, UK and ${ }^{2}$ Clinical Specialities, PEACH Unit, School of \\ Medicine, MVLS, University of Glasgow, Royal Hospital for Sick Children, Glasgow, G3 8SJ
}

In our previous study, we demonstrated that in young healthy lean women consumption of High Energy Nutritional Supplement drinks (HENSD) enhances daily energy intake and therefore promotes positive energy balance ${ }^{(1)}$. Previous evidence suggests that acute changes in energy balance may modify fasting and postprandial concentrations of triglycerides (TAG), glucose and insulin ${ }^{(2,3)}$. This study aims to find out that whether consumption of HENSD in the evening for five days has a detrimental impact on plasma lipids, glycaemia and insulinaemia.

Twenty-three healthy females with a mean (SD) age of 25(5) years participated in a single blind randomised controlled, crossover study. Participants consumed HENSD (594 kcal) or PLACEBO (91kcal) for five days in the evening. Participants were asked to record their dietary intake during days of supplementation. On the sixth day plasma lipids, insulin and glucose concentrations were measured in the fasted state and at 30,60,90 and120 minutes after ad libitum buffet breakfast and lunch.

Averaged daily energy (HENSD, 9.2(0.3) MJ; PLACEBO, 8.2(0.4) MJ, $P=0 \cdot 03)$, carbohydrate (HENSD, $286(11)$ g; PLACEBO, 249 (13) g, $P=0.03$ ) and fat (HENSD, 91.1(6) g; PLACEBO, 70.8 (4) g, $P=0.007$ ) intake were significantly higher in HENSD trial. Data on fasting and postprandial concentration of plasma insulin, glucose, lipids and $\mathrm{HOMA}_{(\mathrm{IR})}$ are presented in table below.

\begin{tabular}{lrr}
\hline & HENSD & PLACEBO \\
\hline Fasting Insulin (mU/L) & $5 \cdot 19(0 \cdot 56)$ & $3 \cdot 47(0 \cdot 27)^{*}$ \\
Fasting Glucose (mmol/L) & $4 \cdot 72(0 \cdot 19)$ & $4 \cdot 55(0 \cdot 29)$ \\
HOMA (IR) & $1 \cdot 08(0 \cdot 13)$ & $0 \cdot 68(0 \cdot 05)^{*}$ \\
Fating total Cholesterol (mmol/L) & $5 \cdot 56(1 \cdot 13)$ & $5 \cdot 30(1 \cdot 04)$ \\
Fasting HDL-Cholesterol (mmol/L) & $1 \cdot 76(0 \cdot 31)$ & $1 \cdot 62(0 \cdot 29)$ \\
Fasting LDL-Cholesterol (mmol/L) & $3 \cdot 39(0 \cdot 84)$ & $3 \cdot 23(1 \cdot 01)$ \\
Fasting TAG (mmol/L) & $0 \cdot 88(0 \cdot 30)$ & $0 \cdot 83(0 \cdot 27)$ \\
Insulin AUC (mU/L) & $24 \cdot 22(3 \cdot 67)$ & $26 \cdot 24(4 \cdot 11)$ \\
Glucose AUC (mmol/L) & $5 \cdot 46(0 \cdot 21)$ & $5 \cdot 51(0 \cdot 34)$ \\
TAG AUC (mmol/L) & $0.97(0 \cdot 35)$ & $0 \cdot 99(0 \cdot 38)$ \\
\hline Values are presented as mean \pm SE $(n=11) *$ Significantly different $(P<0 \cdot 05)$ from HENSD. Postprandial
\end{tabular}

In conclusion, short-term supplementation with HENSD can be expected to reduce insulin sensitivity but have no impact on fasting lipids and postprandial lipemia, insulinaemia and glycaemia.

1. Fatima S, Gerasimidis K, Tsiountsioura M, Arvanitdou I, Wright C, Malkova D (2013) PP197-Mon Impact of high energy nutritional supplement drinks on energy intake, appetite measures, appetite hormones, and rate of gastric emptying. Clinical nutrition (Edinburgh, Scotland) 32, S195.

2. Smith GI, Magkos F, Reeds DN, Okunade AL, Patterson BW, Mittendorfer B (2013) One Day of Mixed Meal Overfeeding Reduces Hepatic Insulin Sensitivity and Increases VLDL Particle But Not VLDL-Triglyceride Secretion in Overweight and Obese Men. The Journal of Clinical Endocrinology \& Metabolism, 98(8), 3454-62.

3. Bellou E, Maraki M, Magkos F, Botonaki H, Panagiotakos DB, Kavouras SA, et al. (2013) Effect of acute negative and positive energy balance on Basal very-low density lipoprotein triglyceride metabolism in women. PLoS One, 8(3), e60251. 